Technical Status of the

Space Shuttle

Main Engine

(NASA-CR-168650) TECHNICAL STATUS OF THE
(National ACademY

SPACE SHUTTLE MAIN ENGINE (National $42 \mathrm{p}$

Unclas

$00 / 20 \quad 11763$

Ad Hoc Committee for Review of the

Space Shuttle Main Engine Development Program

Assembly of Engineering

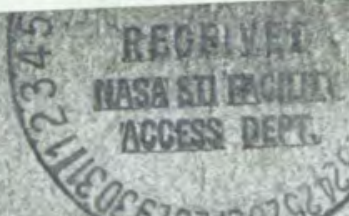
82822892

NOV : 1 : 


\section{Technical Status of the Space Shuttle Main Engine}

A Report of the Ad Hoc Committee for Review of the Space Shuttle Main Engine Development Program Assembly of Engineering National Research Council

NATIONAL ACADEMY OF SCIENCES

Washington, D.C. March 1978 
NOTICE

The project that is the subject of this report was approved by the Governing Board of the National Research Counc11, whose members are drawn from the Councils of the National Academy of Sciences, the National Academy of Engineering, and the Institute of Medicine. The members of the comititee responsible for the report were chosen for their special competences and with regard for appropriate balance.

This report has been reviewed by a group other than the authors according to procedures approved by a Report Review Comittee consisting of members of the National Academy of Sclences, the National Academy of Engineering, and the Institute of Medicine.

This study and report were supported by Contract No. NASW-3147 with the National Aeronautics and Space Administration.

Coples of this publication are avallable from:

Assembly of Engineering

National Research Council

2101 Constitution Avenue, N.W.

Washington, D.C. 20418 
AD HOC COMMITTEE FOR REVIEW OF THE

SPACE SHUTTLE MAIN ENGINE DEVELOPMENT PROGRAM

Eugene E. Covert, CHAIRMAN

Professor of Aeronautics \& Astronautics

Massachusetts Institute of Technology

David Altman

Vice President \& Technical Director

Chemical Systems Division

United Technologies Corporation

Allen F. Donovan

Sentor Vice President, Technical

The Aerospace Corporation

Don A. Hart

Deputy Director

Rocket Propulsion Laboratory

U.S. Air Force

Maynard L. Pennell

Vice President - Product Development (Retired)

The Boeing Company

William Rostoker

Professor of Metallurgy

University of Illinois at Chicago Circle

Lee $F$. Webster

Manager, Test Products

Engine Test Facility

Arnold Engineering Development Center

U.S. Air Force

Robert B. Young

Vice President

Aerojet-General Corporation

Richard C. Mulready, Special Adviser

Director, Technical Planning

Pratt \& Whitney Aircraft. Group

United Technologies Corporation

Albert J. Evans, Project Officer

Aeronautics and Space Engineering Board

Assembly of Engineering

Laura D'Sa, Administrative Secretary 
ABBREVIATIONS USED IN FIGURES

$\begin{array}{ll}\text { CCV } & \text { Chamber Coolant Valve } \\ \text { FFC } & \text { Final Flight Certification } \\ \text { FMOF } & \text { First Manned Orbital Flight } \\ \text { FPL } & \text { Full Power Level (109 percent RPL) } \\ \text { FPOV } & \text { Fuel Pre-burner Oxidizer Valve } \\ \text { FRF } & \text { Flight Readiness Firing } \\ \text { HPFP } & \text { High Pressure Fuel Pump } \\ \text { HPFT } & \text { High Pressure Fuel Turbine } \\ \text { HPFTP } & \text { High Pressure Fuel Turbopump } \\ \text { HPOT } & \text { High Pressure Oxygen Turbine } \\ \text { HPOTP } & \text { High Pressure Oxygen Turbopump } \\ \text { LPFTP } & \text { Low Pressure Fuel Turbopump } \\ \text { LPOTP } & \text { Low Pressure Oxygen Turbopump } \\ \text { MCC } & \text { Maln Combustion Chamber } \\ \text { MFV } & \text { Main Fuel Valve } \\ \text { MOV } & \text { Main Oxidizer Valve } \\ \text { MPTA } & \text { Main Propulsion Test Article } \\ \text { OPOV } & \text { Oxidizer Pre-burner Oxidizer Valve } \\ \text { P. A. } & \text { Pressure Actuated } \\ \text { PFC } & \text { Preliminary Flight Certification } \\ \text { RPL } & \text { Rated Power Level } \\ \text { SSME } & \text { Space Shuttle Main Engine } \\ & \end{array}$




\section{PREFACE}

Almost from the start of the program, a succession of both technical and administrative problems has caused delays in the development of the main engines for the nation's space shuttle, the principal transportation system for both civilian and military operations in space in the $1980^{\prime} \mathrm{s}$.

As the time approaches for determining the readiness of the space shuttle for its first manned orbital flight, scheduled for March 1979 , the Subcomittee on Science, Technology, and Space of the U.S. Senate Committee on Commerce, Science, and Transportation has sought assurance that the engines will perform safely and reliably. While the Subcommittee recognizes that the National Aeronautics and Space Administration conducts extensive reviews of the space shuttle program and, in addition, receives separate, continuous evaluations from NASA's Aerospace Safety Advisory Panel and specific ad hoc reviews by special groups, the Senate has called upon NASA to initiate on behalf of the Subcomittee an independent assessment of the engine system to be conducted by the National Research Council's Assembly of Engineering.

In a letter to the NASA administrator, Robert A. Frosch, dated December 14, 1977, Senators Adla1 E. Stevenson and Harrison L. Schmidt observed:

Recognizing...that the main engine represents a major technology advance and...that the engine development continues to experience difficulties, we are concerned whether everything possible is being done to assure development of a safe and reliable engine system... We would ask the [National Research Counc11] committee to give particular attention to questions of safety of the main engine during both the orbital flight test and operational phases of the shuttle program... We ask that this independent review...be completed prior to the end of February 1978 so that it can be considered during the FY 1979 authorization hearings. 
Accordingly, the National Research Counctl's Assembly of Engineering organized the ad hoc Committee for the Review of the Space Shuttle Main Engine Development Program to conduct the study.

The shuttle main engine requires high-speed and high-pressure turbopumps. Because this technology is relatively new, there are few experts with the relevant background and experience in such rocket propulsion systems. The members of the committee have broad competence and experience in dealing with such advanced systems.

One such advance is the XIR-129, an experimental engine that was tested but never made fully operational. Its development led the committee to draw upon the knowledge of Richard Mulready of Pratt \& Whitney Aircraft, a Division of United Technologies Corporation, which designed and developed the XLR-129 under Air Force sponsorship. Mr. Mulready assisted the committee as a special adviser.

The committee met first January 30-31, 1978, and twice since, on February 16-17 and February 23-24, including a site visit to the Rocketdyne Division of the Rockwell International Corporation in California to witness the work in progress on the main engine. Clearly, the committee's study has been conducted with great speed and intensity in order to meet the deadline set for it by the Senate Subcomittee.

The committee is grateful for the cooperation and documentation provided by NASA and Rocketdyne to enable the members to become quickly familiar with the problems and prospects of the shuttle main engine program. Moreover, the committee acknowledges the assistance of members of earlier technical review groups who described the findings of their studies at its first meeting -- in particular, H.E. Grier, EG\&G Co., Chairman of NASA's Aerospace Safety Advisory Panel, and G. Elverum, TRW, Chairman of the Space Shuttle Main Engine Panel of the Space Shuttle Review Team, who are neither NASA nor contractor employees.

Finally, the commlttee expresses 1ts thanks to Alexander H. Flax, President of the Inst1tute of Defense Analys1s, who, although unable to particlpate fully as a member of the comittee, attended the committee's first meeting and particlpated in its inftial deliberations. 
INTRODUCTION AND SUMMARY

The space shuttle, a hybrid of spacecraft and airplane engineering, is the nation's most significant undertaking in manned space flight since the Apollo program. The shuttle consists of a manned orbital vehicle, launched by three identical liquid-propellant main rocket engines and two strap-on solld-propellant motors, or boosters. The main engines are built into the vehicle. The solid-fuel boosters are to be jettisoned about 2 minutes after the launch, when the shuttle reaches an altitude of some $25 \mathrm{miles}$; the boosters are intended to be recovered and reused. When fully developed, the shuttle will be a reusable, versatile vehicle transporting people, materials, experiments, and objects such as communications satellites into orbit and returning to earth to land like a conventional alrplane. Each operational shuttle is designed to make at least 55 round trips into space, returning to an airport strip.

Flight tests of the shuttle orbiter, involving approach and landing without any of the rocket engines, have taken place after it was launched from a modifled Boeing 747 aircraft. The next major milestone of the program is a manned orbital test flight. The committee considers it appropriate and wholly consistent with all previous alrcraft experience to have a test pilot aboard the machine on its first flight. This increases the operational flexibility and, thus, the likelihood of success for the first manned orbital flight.

The successful operation of the shuttle is based on advances in the operational state-of-the-art of its main engine, particularly with respect to its reusability and to increased performance levels of its components in terms of power per pound. The development of such an operational engine requires a greater step forward in technology over the J-2 rocket, which was used in the two upper stages of the Saturn vehicle that launched the Apollo spacecraft to the moon, than the J-2 did over its predecessor, the RL-10 engine. However, any risk Involved in making such an advance is reduced by the knowledge and experience gained through the development of the USAF Rocket Propulsion Laboratory-Pratt \& Whitney experimental XLR-129 engine and the sub- 
sequent NASA Marshall Space Flight Center-Pratt \& Whitney turbomachinery program that produced turbopumps for an engine of 350,000 pounds of thrust. These two programs were experimental and, in fact, were not intended to reach the operational stage. Nevertheless, they clearly anticipate the successful development of the space shuttle main engine.

Major developments of new flight vehicles have traditionally proceeded by stages, with provision made for alternative approaches along the way in the design and construction of components.* Customarily, the overall system is separated into clusters and subclusters representing different components and functioning assemblies. These are designed and tested separately under simulated operational conditions, then redesigned to correct any problems or malfunctions, and ultimately qualified first for peak performance and then long-term service. Often, when major innovations are required, more than one approach to a design is initiated in parallel and constructed and tested separately. Later, the best design, possibly with modifications, is chosen and the others are discarded. When component performances have been validated, entire assemblies are then tested for coordinated functions. Finally, the complete engine is put through a series of tests under full power to assess proof-of-flight capability. Such a step-by-step, conservative approach provides opportunities to test each piece under conditions that exceed the demands of operational performance. In this way, it becomes possible to anticipate unexpected events and to plan for contingencies that may arise in flight testing. This is clearly a careful, costly, and lengthy approach. NASA's past successes in major developments of flight vehicles have led the agency and its contractor for the shuttle development to rely more heavily on computer computations to reduce the need to evaluate new designs by testing and, consequently, to reduce the need for redesign work. Thus, unlike such previous programs as Apollo, the development strategy for the shuttle program, including its main engine development, has been described as "fully concurrent, success-oriented" -- a strategy based on the assumption that each piece of development hardware and its subsequent verification test will succeed on the first attempt. For the most part, the development tests employ an engine configuration assumed to be the same as the operational hardware to be used for the manned orbital flights. Further, the parts are manufactured on production tooling. Such a strategy offers potential savings in costs by eliminating parallel and possibly redundant development and test hardware.

It may be that this strategy already has saved time and money, inasmuch as the quantity of hardware' and spare parts have been reduced significantly. However, if or when malfunctions occur during the testing of the operational engine, new hardware may need to be designed, constructed, and retrofitted, causing delays in the program.

*See Appendix A for a detailed discussion. 
Indeed, such an eventuality has befallen the shuttle main engine. As often happens in the course of developing a complex, highperformance system, NASA and Rocketdyne have encountered some technical problems related mainly to the rotating machinery and the highpressure turbopumps which have led to engine test malfunctions and delays of test sequences. At the time the committee conducted its study in February 1978, some of the problems were unresolved. Solutions have been proposed but are yet to be proved correct through testing.

The committee understands that NASA is considering conducting the first six manned orbital flights of the space shuttle at 100 percent power of the "rated power level" of the maln engines. Later flights will require a thrust level that is 9 percent greater than rated power or "full power level" in order to launch the full shuttle payloads into orbit. The requirements for safety and reliability of the engine operating at full power place more stringent demands on the various components of the engine than when it operates at the lower, rated power, level. Thus, even after the engine is qualified for the first manned orbital flight, additional development may be necessary to qualify the engine at full power. The development plan under consideration calls for the certification of the engine at 100 percent power as a prerequisite for the first manned orbital flight and a subsequent certification of the engine at 109 percent power. This two-stage certification strategy represents a change of philosophy reached by NASA during the period of the committee's review.

It is especially important to understand that while the program has been underway for nearly six years and is now within one year of the first scheduled manned orbital flight, the development of the engine is not as far along as the timetable may suggest. The initiation of engine development was delayed 9 months for nontechnical reason. Thus, in terms of accumulated test experience, the current state of development of the space shuttle main engine is relatively immature.* The committee finds that the problems now being encountered are not alarming but rather typify the early stage of any similar new technological development.

The solution to the problems encountered in the shuttle main engine involves the redesign or modification of parts in the rotating machinery, with each change affecting the performance of this closely coupled engine. While many elements of the engine development point to the ultimate success of the program, incorporation of the changes and the tests to assure their effectiveness could result in delays. The ambitious timetable may have to be extended to avold a first manned orbital flight with a high risk factor.

\footnotetext{
*In the development of such a complex system, experience is gained slowly at first, but as work proceeds experience accelerates rapidly.
} 
In the final analysis, the amount and results of testing performed on the ultimate flight-configured engine will determine the timing and safety and reliability of the engine for the first manned orbital flight. The committee expects that, at the completion of the planned testing, adequate data should be available by late summer or early fall 1978 to enable NASA to develop a realistic schedule. The comittee concludes that the appropriate time for NASA to review the shuttle flight schedule is when these data are available. The data may suggest that a delay is desirable to allow for a more realistic rate of testing, to provide leeway for as yet unforseeable changes, to incorporate proof-tested parts in the main propulsion test article (MPTA) and flight engines and, perhaps most important, to allow adequate time to analyze root problems and seek out their solutions rather than attempt to cure symptoms.

In addition to these conclusions, the committee also makes a number of recommendations. Some address the need to adhere to currently established testing criteria and standards in spite of the pressures imposed by an ambitious schedule. The committee recommends testing the engine at an added safety margin above the power level of the first manned orbital flight and tearing down the engines for inspection following at least the first and sixth flight. Additional recommendations concerning the need for future design work and component testing are also made in this report.

The balance of this report provides a brief description of the shuttle main engine and how it operates, its present status, the committee's perception of the critical issues and their consequences, and, finally, the conclusions and recommendations. In making this assessment of the shuttle main engine program, the committee always recognized two basic requirements: First, the need to develop main engines with performance levels that will enable the first manned orbital flight to be as reliable and safe as America's earlier manned space flights, and then to achieve full power for later flights. Second, the need to maintain full power performance in the same engines for at least 55 missions of each shuttle.

Based on the experience of the program so far, the comnittee sees no reason to suggest that a safe and rellable main engine cannot be developed ultimately for the manned orbital flight tests and the later operational flights. 
SPACE SHUTTLE MAIN ENGINE - A BRIEF DESCRIPTION

The main engine is a machine for producing the thrust necessary to launch the space shuttle into a low orbit around the earth.

The shuttle has three main engines that operate on cryogenic liquid propellants -- liquid hydrogen, the fuel, and liquid oxygen to burn the hydrogen. Each propellant is pumped to a very high pressure by two pumps. One is a low-pressure pump that increases the pressure several hundred pounds per square inch. Then a high-pressure pump increases the hydrogen pressure to 6,200 pounds per square inch and the oxygen to 4,600 pounds per square inch. Such pressures are greater than those of any previous operational hydrogen/oxygen engines, e.g., the RL-10 and $\mathrm{J}-2$, though such pressures have been developed in two experimental programs.

Each of the four pumps (low- and high-pressure hydrogen, low- and high-pressure oxygen) is driven by a power source from within the engine. The two high-pressure pumps are each powered by a turbine mounted on the pump shaft (Figure 1). The turbine is driven by a hot, fuel-rich gas. The gas is produced in a pre-burner where a relatively large amount of hydrogen reacts with a small amount of oxygen. The product of this combustion is a mixture of hot hydrogen and superheated steam. The two low-pressure pumps also are driven by turbines. The low-pressure hydrogen pump turbine uses hydrogen gas tapped from elsewhere in the cycle which is described later. The low-pressure oxidizer pump, also described later, is driven hydraulically by liquid oxygen that is tapped from elsewhere in the cycle.

The hydrogen flowing from the high-pressure fuel turbopump is an effective coolant as well as a source of a high energy. In this engine it follows several paths to cool the critical parts where combustion occurs or hot gases flow. In its cooling function, the liquid hydrogen is heated and vaporized. Most of the gaseous hydrogen is routed to the two pre-burners, which serve as gas generators for the turbines that drive the high-pressure pumps. A smaller amount of the gaseous hydrogen is piped to the turbine that drives the low-pressure hydrogen pump. Most of the liquid oxygen is channeled directly to the main 


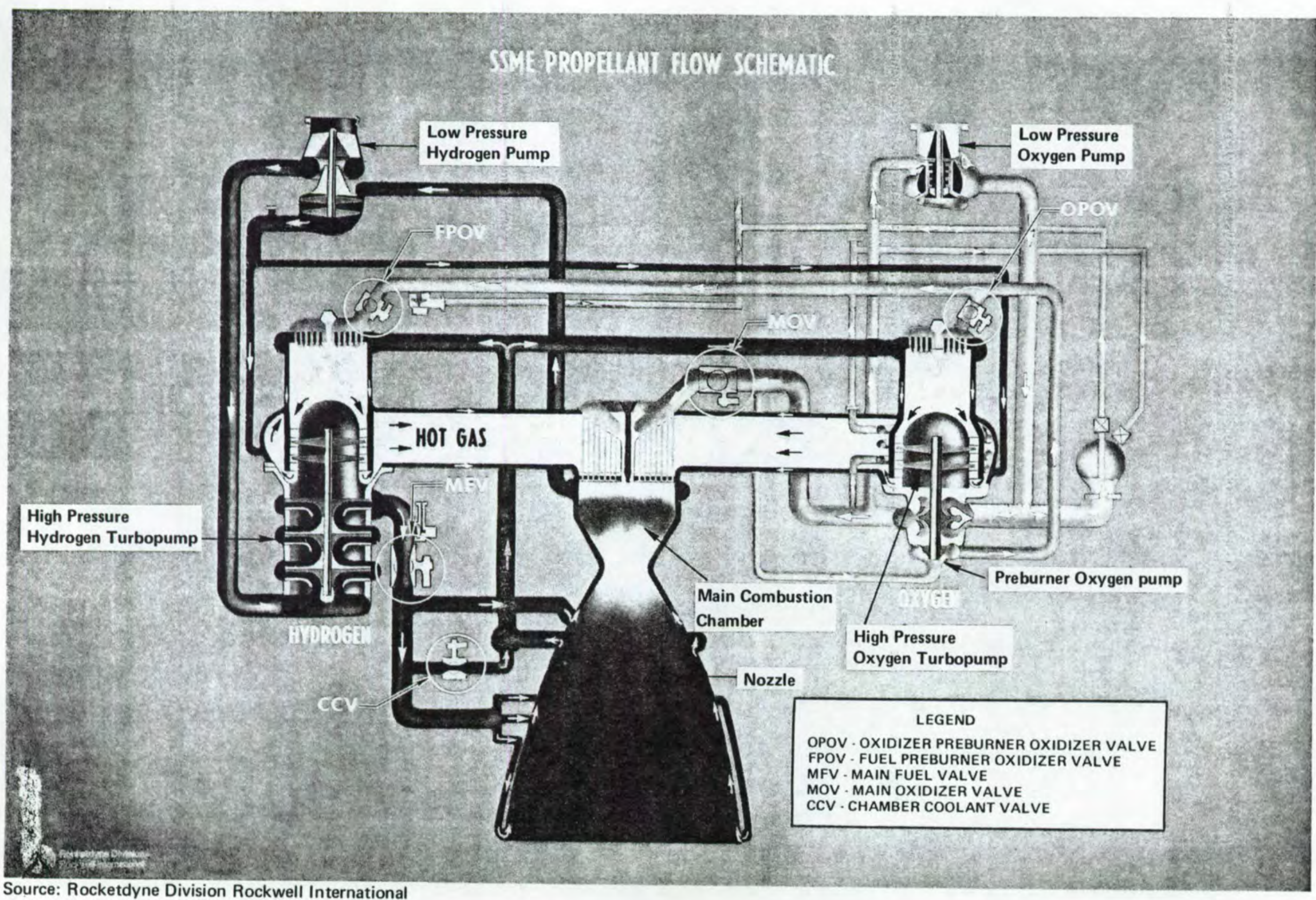


combustion chamber. A small amount of the liquid oxygen enters a special very high-pressure pump stage mounted on the end of the shaft of the high-pressure oxidizer pump. The oxygen flowing at this stage is under pressure of 7,650 pounds per square inch, the highest pressure in the entire engine. Then the pressurized liquid oxygen is fed to the two pre-burners, where part of the hydrogen is burned. The pre-burner exhaust is used to drive the high-pressure pump turbines.

The main event now takes place. The pre-burner exhaust, consisting of hydrogen and superheated steam, mixes with the primary highpressure 1iquid oxygen in the main combustion chamber, where combustion takes place at high pressure. The products of combustion, consisting mostly of superheated steam, pass through a constriction, the nozzle throat, and expand rapidiy to a high velocity. Over 1,000 pounds per second of combustion products moving at high velocity is the action that produces the reaction or thrust for the vehicle.

While the basic concept is simple - cold liquid hydrogen and oxygen coming in and superheated steam propelled out -- the various flow paths need meticulous control. Such control is provided by valves at critical points in the engine. The valves are activated by a special purpose digital computer called the engine controller, which converts such data as pressure and temperature into position signals. For this operation, the controller is a closed loop device, 1.e., it is self-correcting. The controller also monitors signals from sensors mounted in the engine, so that it can quickly shut down the engine when a malfunction is detected.

Another function of the controller is to control carefully the engine start-up and shut-down. Without careful control, parts of the engine may overheat and even melt. Destructive fires may take place by oxygen washing over hot metal surfaces. Prior to start-up all four pumps are pre-chilled by liquid propellant circulating through them. Sparkplug-1ike igniters in both pre-burners and the main combustion chamber are energized. The main hydrogen valve opens first. As the cold hydrogen comes in contact with the engine parts it is gasified. The warm hydrogen gas begins to turn the turbines. The oxidizer control valves then open in a precise sequence: the Igniters initiate combustion first in the pre-burners and then in the main combustion chamber. The shut-down is essentially the reverse of this process: the oxidizer flow is turned off, then the hydrogen flow. The controller is designed to ensure that all the oxygen is purged from the 11nes downstream of the valves before the hydrogen flow is shut off. This is necessary to reduce the possibility of a "hot spike" or high temperature surge at shut-down.

The space shuttle engine has severe requirements of light weight, compactness, high absolute thrust, and high thrust per pound of fuel burned. Much of the reduction in weight of the main engine is achieved by two basic design philosophies. One integrates the system as fully as possible. This implies, in part, an exceedingly compact, inter- 
active arrangement. Compactness provides economies in size and welght. It also implies extremely high power densities in the fuel and oxidizer pumps. The small separation of hot and cold gases, of fuel gases and oxidizer gases, and of liquids and gases gives rise to potential hazards that impose extremely stringent demands for reliable construction. The other basic design philosophy is to weld as much of the assembly as possible. This eliminates heavy flanges and bolts, thus saving substantial weight and reducing the size of the assembly. Because welds are sometimes a source of inclpient cracks, standards of quality control and inspection must be very high. Both NASA and Rocketdyne appreciate this need and are working to ensure that high standards are met in production.

This brief description marks the shuttle main engine as a complicated, high-performance machine made up of a number of interacting components and, like its predecessors, designed to provide a high thrust per unit of weight. Unlike its predecessors, it is designed to be reusable for many flights to orbit. Accordingly, the successful development of the shuttle engine is a prodigious engineering challenge. 
CURRENT STATUS

On Apri1 4, 1972, Rocketdyne was authorized to proceed in developing the space shuttle main engine - 9 months after it was selected as the contractor to develop the engines. Engine system testing began in June 1975, nearly 15 months later than the original schedule. Operation of the engine at rated power level was first achieved in March 1977 .

In the course of the development NASA expects to accumulate about 80,000 seconds ( 1,333 minutes) of operating experience on the main engines. By February 25, 1978, a total of only 11 minutes of operation at rated power level had been accomplished, with no operating time at full power level. A typical flight will require about 8 minutes of engine operation, most of it at close to rated power level for the early flight tests and at full power level for the later operational missions. The engine's ability to run in demonstration tests at flight power level for a total duration of at least five flights (40 minutes) without significant malfunctions is one of NASA's essential prerequisites to its use in actual flight.

Based on the test time accumulated through February 1978 at rated power, the engine is still relatively early in its development. It is at a point at which running time is accumulating slowly. Development programs are designed to uncover problems as rapidly as possible early on, and to demonstrate performance and rellability later. As the problems are resolved, the rate at which running time is accumulated increases rapidly to enable performance and rellabllity to be demonstrated relatively quickly.

In tests, there have been a number of engine test malfunctions, some requiring substantial reconstruction and, therefore, causing delays. This is a practical consequence of component proof testing. The types of malfunctions have included cracks, fractures, leaks, and lack of rigidity. It will not be a simple matter to correct such problems, but nelther do they involve major redesigns.

As the testing proceeds and more is learned about the engine, a series of changes or modifications will have to be developed to achleve the required performance and durability. Many of these changes, but 
not all, will have to be fully incorporated before the engine can be qualified for first flight. Thereafter, a second program of qualification will be required to achieve an engine capable of operating at full power, 1.e., 109 percent of the rated power level. At present, some changes are 1ikely to be required to raise the power level and simultaneously increase the life of the engines to the original objective of $7 \frac{1}{2}$ hours. This may upset the overall process of developing the engine in view of the extent of the changes that might be necessary. 
TECHNICAL CONCERNS

Operation at rated power level has revealed a number of problems. Most of these difficulties are found in the rotating machinery, 1.e., the four, high-speed, turbine-driven centrifugal pumps that deliver the liquid hydrogen and oxygen propellants to the combustion chamber under high pressure.

Examples of the difficulties are high vibration-induced stresses in the high-pressure fuel pump turbine blades, major leakages through shaft seals in the high-pressure oxygen pumps, inability of the fuel pump to operate at the inlet propellant pressures for which it was designed, and low efficiencies. These low efficiencies result in increased power requirements and thus increased turbine inlet temperatures to ensure adequate pump delivery. This occurs because a spectfied engine thrust requires a specifled rate of propellant flow.

The committee notes a significant dichotomy in the state of subassembly development testing. Such engine components as the combustion chamber, the nozzle, the pre-burner, the valves, and the computercontroller were tested as components and are performing relatively satisfactorily in general. The testing of the high-pressure turbopumps as components also had been planned, and a facility had been built at Rocketdyne for the purpose. Testing on this rig was initiated on May 1, 1975, and concluded on September 12, 1977, with only 161 seconds on the oxygen pump system and 111 seconds on the hydrogen pump system. Some of the difficulties encountered with the test rig were caused by the very high system pressures that required heavy hardware that was hard to manage. Thus, long delays resulted when changes were made. Rocketdyne and NASA concluded that component testing of the highpressure turbopumps could not be carried out at a rate that would be useful in the development program. As a result, NASA and Rocketdyne decided to conduct turbopump development tests by running the pumps as part of the total engine system. The committee considers this decision has great bearing on any examination of the problems in the turbopump. For instance, it precludes testing the high-pressure turbopump at conditions other than the normal operating conditions. The decision 
also has the effect of preempting the use of hardware for turbopump development that could otherwise be used for engine performance development testing.

The lack of an adequate test rig to conduct component tests expeditiously outside the engine appears to be the primary reason that the turbopump problems were not discovered before last summer, during the intial engine tests at the rated power level.

NASA and Rocketdyne hold that the engine tests at rated power level have provided the data necessary to identify any deficiencies in the engine and the high-pressure turbopump, and the data necessary to formulate corrective actions. Insofar as the committee is aware, however, no rocket engine using turbopumps has ever been produced without extensive development testing of the turbopumps first as components.

In this connection, a facility for component testing of highpressure turbopump systems was developed for the XLR-129 program. While an adequate turbopump test rig cannot be made avallable to contribute to the development of the main engine for the first flight, past experience suggests that such a test $\mathrm{rig}$ could be very useful in the long run for identifying and solving problems assoclated with durability and reliability. Accordingly, NASA and Rocketdyne may want to explore the most effective way to acquire an operating component test rig for the rotating machinery. concern:

The committee considers the following to be of primary technical

- The high-pressure oxidizer turbopump is critical to the performance and safety of the main engine. While the committee recognizes the design changes being made, it notes a considerable number of these are yet to be verified. Nevertheless, the complexity of the design, the relative flexibility of the shaft and housing, the complicated load paths, the extremely high performance demands, and the planned multiple reuse suggest that a back-up shaft and housing design be initiated. While a long lead-time is involved, a parallel development seems to be in order for this key assembly.

- The heat exchanger downstream from the oxidizer turbopump pre-burner is an extremely complicated welded assembly. It is located in a position where inspection is difficult. While no recent incidents have been attributed to heat exchanger failures, the committee is concerned that a fallure of the heat exchanger could be catastrophic. Therefore, this item warrants continued management attention. 
- The preliminary flight certification of the engine requires the development of a specific set of hardware that will meet the test requirements. Because the main engine is a closed cycle machine in which the performance of each individual component such as a valve, say, or a turbine-driven pump or a heat exchanger affects all the other components, it is essential that the number of changes between successive tests be kept as low as possible, particularly when the performance of the component is involved.

- Three fallures in the high-pressure fuel turbopumps have been attributed to high cycle fatigue in the turbine blades. The first two incidents (which occurred at accumulated times of 313 seconds and 2,973 seconds) were confirmed by fractographic analysis. The third fallure is inferred because the turbine was destroyed by fire during testing. While there is general agreement among the experts that the material used for fabricating the blades is suitable, the committee considers that a more complete characterization of the material is needed. The problem of high cycle fatigue is common in turbine development, and the committee is confident this problem will be solved. While the turbine blade problem* has recelved considerable attention and although it may require a year or so to provide a permanent solution, the committee finds the difficulties to be characteristic of the kinds of problems encountered in the development of any new turbine system.

Not unexpectedly, many components are being redesigned or modified to a greater or lesser extent. For instance, all four turbopumps (low-pressure and high-pressure, fuel, and oxidizer) are being altered, sometimes by several changes simultaneously. One indication of the present state of the engine development is that the turbine inlet temperature of the high-pressure fuel turbopump is running some $450^{\circ} \mathrm{F}$ above the design value of $1,271^{\circ} \mathrm{F}$ at 100 percent power level. The program developed to reduce the temperature is outlined in Figure 2. It is not now certain that each of the changes will produce the predicted temperature reduction. It is certain, however, that each of these changes will affect the performance of the rest of the engine. In effect, a whole succession of configuration changes is undergoing tests. Because changes are being made in several other parts of the engine as well, it appears likely that the development will take more time than planned. This, too, is to be expected in any major new development. In fact, the more advanced the design, the longer the

*See Appendix B for more details 


\section{HPFTP TURBINE TEMPERATURE REDUCTION}

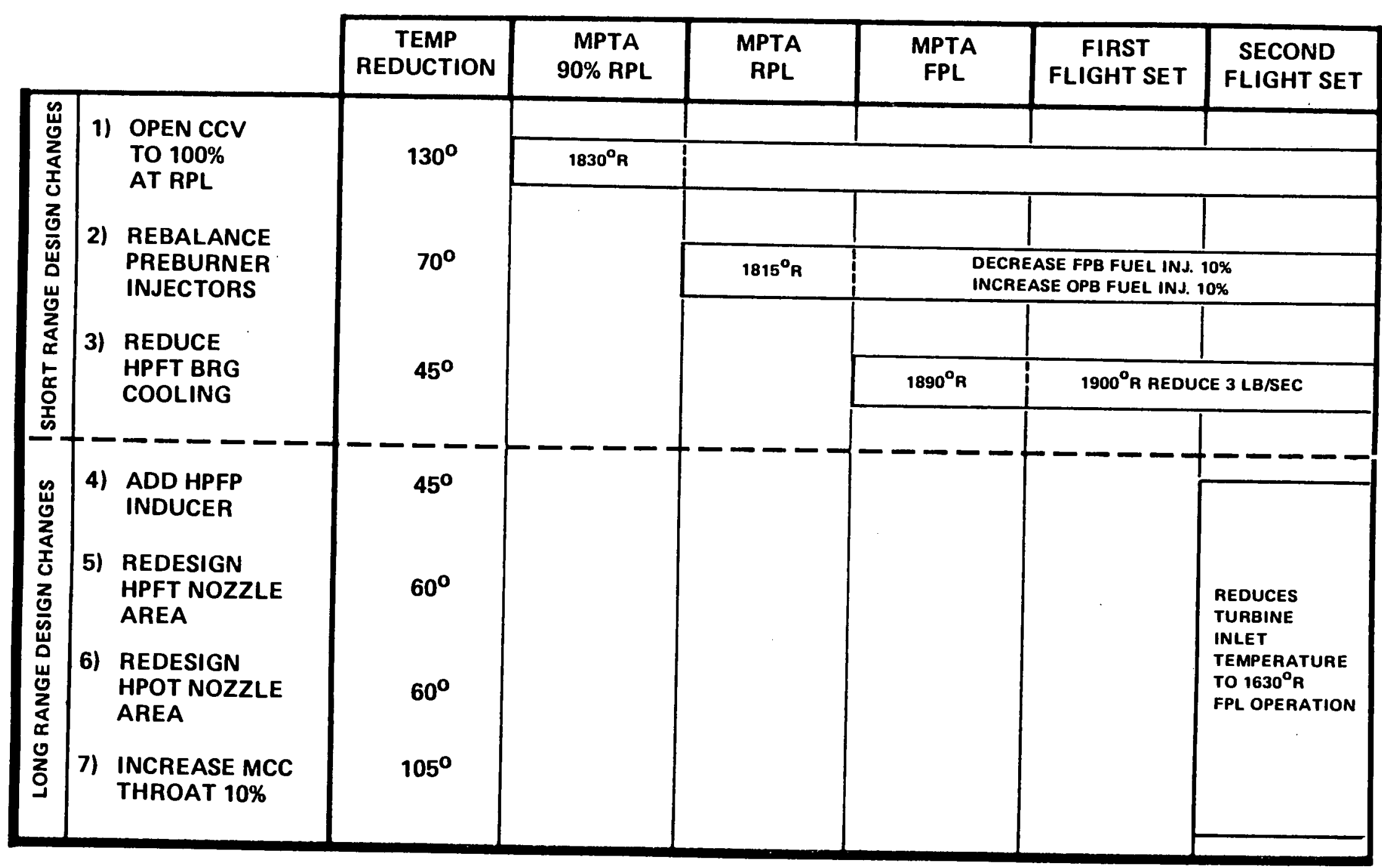

Source: Rocketdyne Division Rockwell International 
development process is $11 k e l y$ to take. The time required to correct test-induced fallures ranges from a few weeks for simple modifications to over a year for more complicated redesigns. Note that some of these redesigned parts may not be needed for the first manned orbital flight. Full power operations, however, require such modifications.

Fortunately, many elements of the engine program give evidence that the desired performance, durability, and safety can be achieved. Thus the comnlttee has no doubt about the successful final outcome. 
SCHEDULE CONCERNS

To bring together all the necessary components for a safe, reliable, and reusable engine without undue and costly delays to the scheduled f1rst manned orbital flight requires managerial skills of the first order. Such skills are particularly necessary for a program in.whtch decisions are made seven or elght years before the main everit. In this case, the schedule needs to possess some flextb1lity. Slippages of a month or two in a program of 100 months, Involving the development of a new, technically challenging system, do not represent a serlous defect. Indeed, a 10 percent to 12 percent extension in schedule should be regarded as nomal and not an anomaly.

However, as ciftical milestones approach, intense pressures to meet the schedule are apt to develop. Frequently, this involves considerable parallel effort and overtime work. So long as everything goes reasonably well, this causes no untoward problems. But when troubles arise, the potential increases for new, unforeseen difficulties, both technfcal and managerfal. The temptation exists to cut corners, omftting tests of components for instance, to keep to the schedule. Moreover, human fatigue or stress can lead to mistakes in judgment.

In such clrcumstances, Increased demands are placed on management to know when to hold to the original schedule and when to allow a slippage. Indeed, a first flight may be delayed and, yet, because of the greater rellabllity attalned through improvements and modifications, the overall program can be benefitted, and the early delay can be made up so that later flights are on schedule.

In the case of the space shuttle main engine, the authorization was delayed by 9 months. This imposed great pressure on the schedule. To deal with this, NASA and Rocketdyne have lald out an ambitious timetable for incorporating and testing newly deslgned parts. The rate of accumulation of engine operating time shown in Figure 3 is clearly based on meeting 1t. Notw1thstanding, the committee considers such an optimistic schedule is not likely to be realfzed in practice because 


\section{ACCUMULATED ENGINE \\ TEST DURATION}

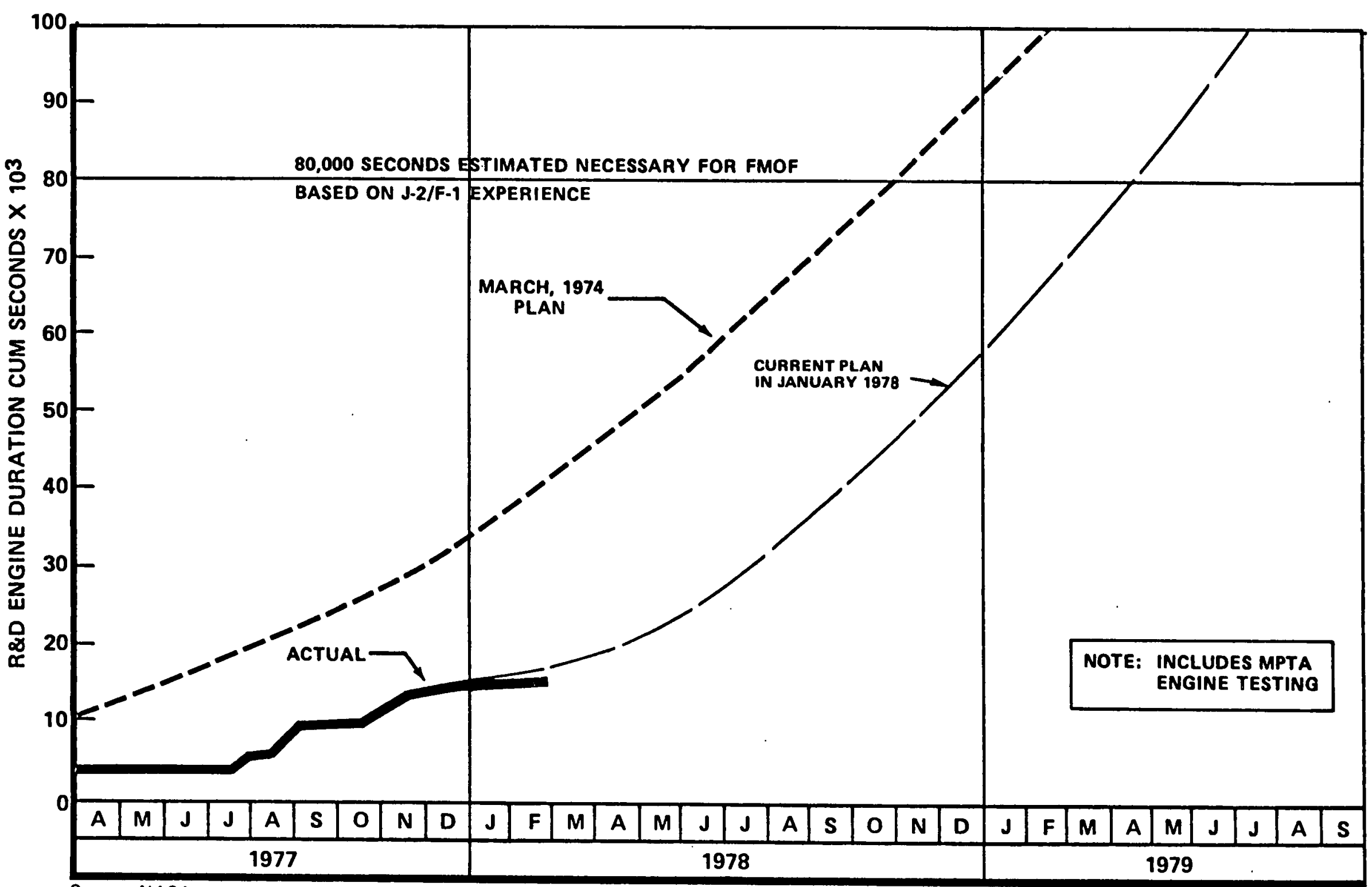


of the small likelihood of success of all the modifications currently in progress.

The completion of tests and evaluation of performance of modified components during the next 5 to 7 months should help substantially in determining the time that will be required to obtain a flightcertified engine. While the comittee recognizes that a successful engine can be developed without component testing of the high-pressure turbopumps, in the absence of any past experience with such a program there is inadequate data to make a rellable prediction of the time required to accomplish the development.

The committee suggests that NASA will need to examine the status of the engine development in late summer, early fall, or whenever data sufficient to assess the engine status becomes available, in order to prepare a precise schedule. The data may show, for example, that the first manned orbital flight is possible within the current schedule. On the other hand, it may show that the optimism is not warranted. Moreover, the data may suggest that a delay is destrable to allow for a realistic rate of testing, provide leeway for further changes, incorporate proof-tested parts in the main propulsion test article and flight engines and, most importantly, allow time to analyze problems and proposed solutions adequately. In the last respect, the committee is concerned that the current schedule is so compressed it generates an atmosphere that seems to inhibit realistic evaluations of the problems encountered so far. 
SAFETY AND RELIABILITY

Safety must always take precedence over scheduling concerns. Because no flight test of the space shuttle main engine is planned prior to the first manned orbital flight, confidence In the safety and rellability of the engines in manned flight must be based upon:

- Safety and rellability designed into the engine

- Testing of flight-configured engines

- Quality control and testing of the three engines when mounted in the orblter for the first flight.

It is Important that the term "flight-conflgured engine" be well understood. "Configuration" means identification of all the parts makIng up an engine. As in any engine development, design changes are made in response to problems as they are uncovered. Thus, early in the development program, the configuration is in a state of change. While total test time in the overall program is an important measure of the maturity of 1 ts development, the amount of testing performed on the flight configuration is the single most important parameter in considering the safety and rellability of the first flight. Figure 4 shows the Improvement in the operating conditions expected from Incorporation of Improved hardware. When this chart was prepared, the contractor had assumed all changes would be fully effective.

Evaluating the "testing of flight-configured engines," therefore, Involves a verification of the extent of engine maturity. Rocketdyne plans to achleve approximately 40,000 seconds ( 11 hours) of firing time on the flight-conflgured engine (F1gure 5) before the first manned orbital flight (FMOF). To accomplish this, the comittee suggests that additional hardware will be required. What is more, additional technical problems are likely to arise in the course of testing.

NASA has divided the preliminary flight certification into two phases. The first phase, labelled PFC-FMOF. (Prellminary Flight 


\section{SSME CONFIGURATION VERIFICATION}

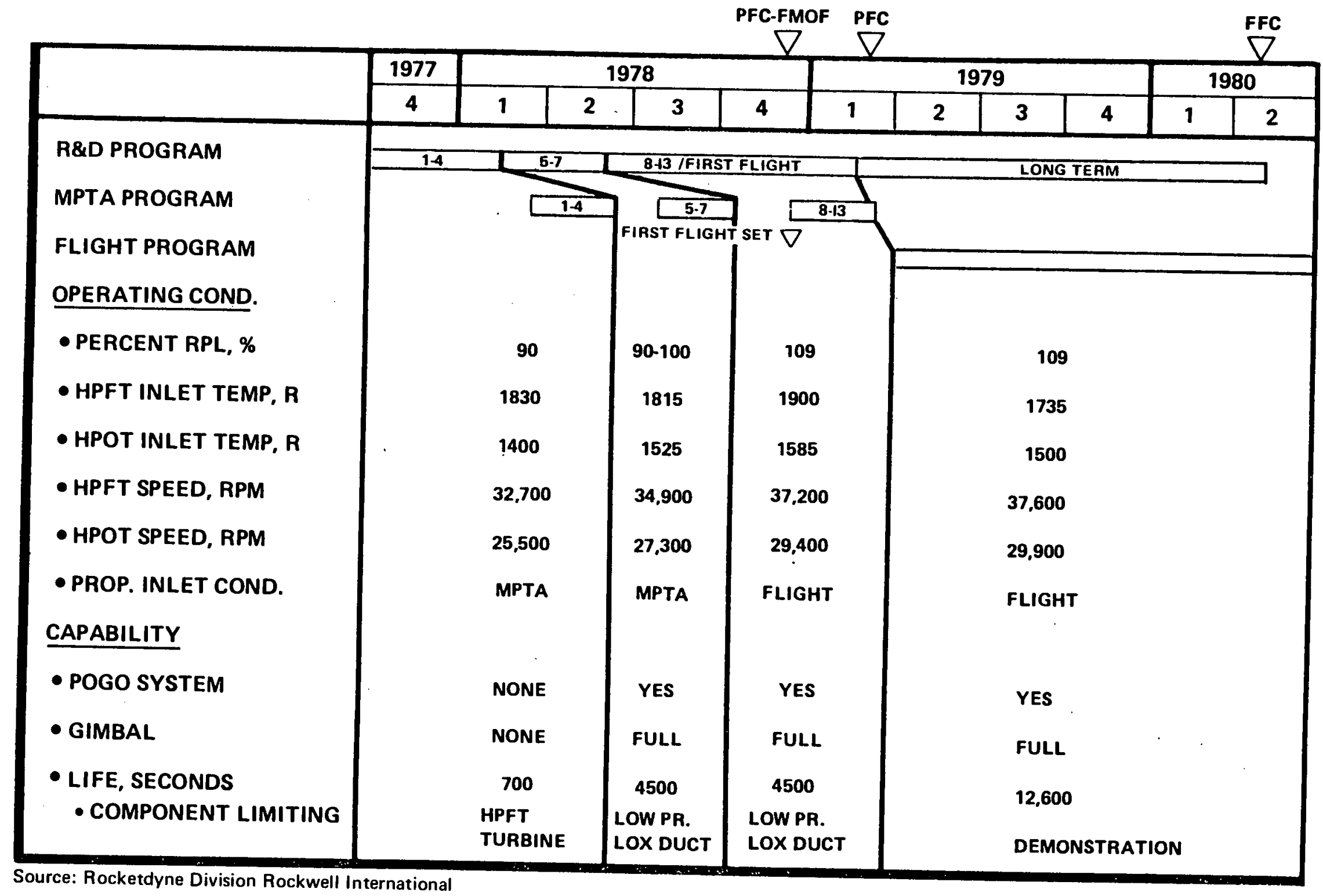




\section{IEST SECONDS ON FMOF CONFIGURATION}

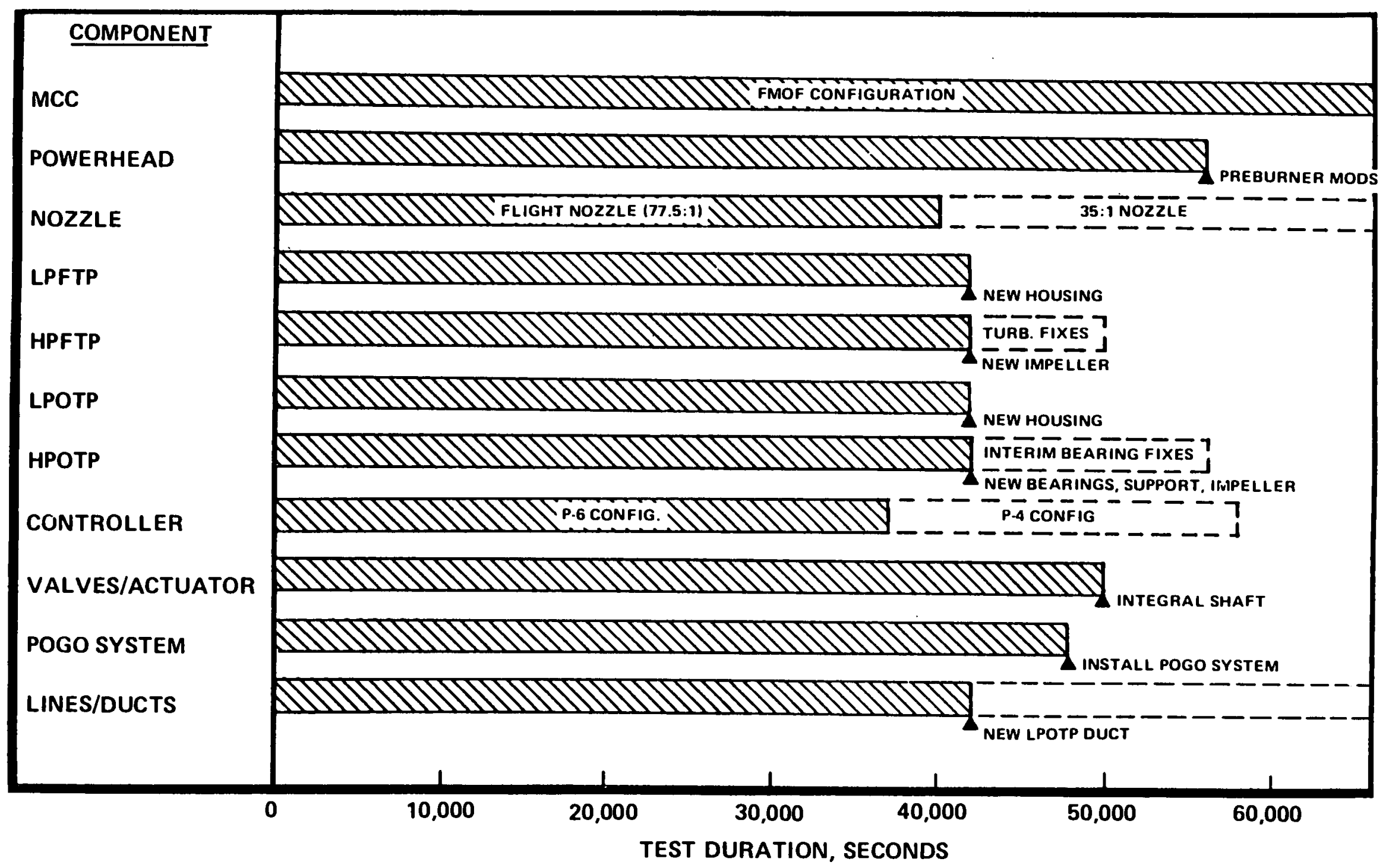


Certification-First Manned Orbital Flight), will achieve the following milestones on a single, flight-configured engine:

- 1 hour total time

- 10 starts

- 50 percent of the firing time at the 109 percent rated-power level with inlet conditions the same as expected in first manned orbital flight. (NASA is considering reducing this power level to 100 percent.)

The current NASA scheduling for the shuttle main engine calls for complete preliminary flight certification (PFC in Figure 4) to be completed before first flight. This complete preliminary flight certification is to be performed on the same engine used in the first phase, or PFC-FMOF, described above. In the second phase, total duration is to be extended to 9,000 seconds ( 2.5 hours), and the number of starts extended to 25. This test duration is more than 12 times a single flight duration; which is an appropriate margin from high-cycle fatigue considerations.

The committee was informed that NASA is giving serious consideration to limiting engine power to 100 percent rated power level for the first manned orbital flight. Data were presented indicating that the mission objectives for this flight, including abort modes, can be achieved at 100 percent rated power level or less. The committee considers this reasonable, but finds it important to demonstrate engine operation at a power level in excess of the mission requirement. The committee suggests that such a safety margin be set at 2 percent (102 percent of whatever power level is selected for the mission).

In addition to the development testing and the preliminary flight certification of the single engine, NASA plans call for tests of the main propulsion test article (MPTA), 1.e., the cluster of three flightconfigured engines fed from a flight-configured main tank. These tests are indicated in Figure 4 as tests 8 through 13. The committee is concerned that the planned testing may be reduced to maintain the schedule.

The last important confidence factor, quality control and testing of the actual flight engines, involves management procedures to ensure that the actual flight engines are identical in every essential respect to those successfully tested during the development, the preliminary flight certification for first manned orbital flight, and the tests of the main propulsion test article. NASA and Rocketdyne have such procedures, which appear adequate to the committee. Acceptance testing on the actual flight engines involves three starts - two at short duration and one at full flight duration. In addition, the actual flight engines for the first manned orbital flight will be tested for 20 seconds on the launch pad in a "hold-down" test. 
If the three safety and reliabllity considerations are handled successfully, as described above, the comittee is confident that the main engines will perform safely in the first manned orbital flight. By this, the committee means that the engine must perform not only without failure, but also without indication of incipient failure, appearance of distress abnormal wear conditions, or borderline values of measured parameters, and so forth. This confidence is also based upon the assumption that the ground testing of flight-configured engines will provide for a reasonable test time at a power (thrust) level 2 percent greater than the power level to be used in first manned orbital fifght. With respect to subsequent flights in the shuttle program, NASA plans to use the first set of three engines on the first six manned orbital flights. No disassembly of the engines after flight is currently planned, only boroscope and visual inspection. The comittee recommends that this inspection be expanded to include engine "teardown" and inspection after the first and sixth flights. If the inspection following first flight reveals no signs of distress and if the engines are performing properly, boroscope and visual inspection after the next four flights are considered adequate.

The committee did not address in detail the approach and schedule for final flight certification, 1.e., assurance of the safety and reliability of the engines throughout their 55 misstons. Improvements in pump efficiency and in main combustion chamber cooling are planned to reduce the fuel turbine inlet temperature to the design level. Most of these changes, listed in Figure 2, are st111 in the design or fabrication stage, leaving proof of capability still to be demonstrated. Reduction of the inlet temperature is essential to the attainment of satisfactory turbine Iffe over the course of the manned missions. Each actual improvement realized in the turbine inlet temperature should be closely monftored and alternative approaches should be developed for any change that falls short of the expected temperature reduction. Only when the engine performance level has stabilized can the final assessment of engine life be completely meaningful. Additional time and additional test hardware are likely to be required to reach final flight certification. 
RECOMMENDATIONS

- It is too early to predict the exact timing of the first manned orbital flight. The committee expects adequate data will be avallable by late summer or early fall of 1978 to plan the first flight schedule more realistically. Because of the number of critical milestones yet to be achieved, the committee recommends that the schedule be reviewed at that time.

- The committee recommends that Rocketdyne acquire an additional engine and critical parts to accomplish the required testing in this period. This hardware can be diverted from the production program into the R\&D program, and replaced in the production program at a later date.

- The committee recommends the initiation of an alternate design of a new high-pressure oxygen turbopump shaft and housing.

- The committee recommends a review of the decision to perform turbopump development tests by running the pumps as part of the engine system to examine alternative options for the long term. NASA and Rocketdyne should explore means of acquiring and operating a componentdevelopment test rig for the rotating machinery. Among the options are: modification of Rocketdyne's existing test rig for the shuttle main engine; use of the component-development test $\mathrm{rig}$ for the XLR-129 experimental program if it is intact and avallable; design and construction of a new test rig utilizing the engineering experience involved in the development and use of the XIR-129 facility. This kind of equipment is likely to prove invaluable throughout the life of the space shuttle transportation system。 
- To minimize future delays in the schedule, NASA and the contractor should allow adequate time to analyze root problems and seek out their solutions rather than selecting technical "fixes" to cure symptoms.

- The minimum preliminary flight certification requirement before first flight, as currently planned by NASA should not be compromised and should be strengthened by a requirement for tests at a power level in excess of that required for flight, as follows:

1. Successful completion of the main propulsion test article program on flight configuration engines with at least two uninterrupted full duration runs at 102 percent of first manned orbital flight power level.

2. Successful completion of at least 10 starts and 3,000 seconds of operation on a single engine of flight configuration. At least 25 percent of this time should be at 102 percent of first manned orbital flight power.

- A complete tear-down inspection of the main engine should be conducted after the first and sixth flights. If there are no signs of distress and if the engines are performing properly after the first flight, a boroscope and visual inspection should be suffictent after each of the next four flights.

- While the heat exchanger has encountered no problems recently, the committee urges that it should continue to recelve management's attention. The heat exchanger system poses a potential threat to the total shuttle system. However, the changes required for a redundant heat exchanger to eliminate this single point threat of fallure seem to be so extensive that provision for redundancy is impractical. Nevertheless, the committee recommends that an alternate design and development should be explored to relocate or reconfigure the heat exchanger system.

- The next step in the engine development should be to increase the power level to a full 109 percent. 


\section{APPENDIX A}

TURBO MACHINERY DEVELOPMENT CONCEPTS

by

Lee F. Webster

\section{Past Approach}

In the past, the U.S. rocket industry has employed component test facilIties for the development of rocket engine pumps and turbines. Such facilities are designed to subject the applicable hardware to the total range of operating conditions required to prove that these components have achleved the design performance and reasonable operability before risking testing of the complete engine system. Use of such facilities allowed detalled measurement of performance, stresses and temperatures without restrictions imposed by the limitations of other engine system components. Thus the testing could be designed to define the strong and weak characteristics of the component, as well as to assess the margin for error available when the component was integrated into the system. Generally, this approach minimized costs incurred from damage to other engine system parts if fallure occurred.

With the growing complexity of rocket systems, component test faclitiles have also become more complex and more expensive, of ten becoming developmental efforts in themselves. Lead times required to design, procure and "debug" such facilities are often measured in years and thus become a major item in planning for the acquisition of a rocket engine.

\section{Space Shuttle Main Englne Approach}

Early Space Shuttle Main Engine program planning was predicated on the construction and use of a component test facllity. However, efforts to use the facility proved to be difficult, expensive and not very frultful in terms of acquiring useful turbo machinery information. Figure A-1 summarizes the accomplishments in terms of the test and running time over a 27-month time. Normally, such testing for past rocket developments would have accumulated at least 10 times more testing. Late in the past year, this approach was abandoned. Future turbo machinery testing is to be accomplished only on engine test stands using the integrated engine assembly as the test fixture. 
SUMMARY OF TESTING AT COCA-1 FACILITY

Initiated May 1, 1975 - Concluded Sept. 12, 1977

\begin{tabular}{llll}
\hline & Tests & Sec & Assemblies Tested \\
\hline COCA 1A & & & \\
LPOTP & 15 & 706 & 4 \\
LPOTP.HPOTP & 24 & 161 & 3 \\
& & & \\
COCA 1B & & & 6 \\
LPFTP & 47 & 2192 & 6 \\
LPFTP.HPFTP & 27 & 111 & \\
\hline
\end{tabular}

Source: Rocketdyne Division Rockwell International

Figure A-1

Results

Because of the lack of a successful turbo machinery test factlity, characterization and verification of the high pressure pump destgns is a pacing item in the development schedule. Some problems have been Identiffed during engine testing and efforts for their solution are now underway, as shown in Figures $\mathrm{A}-2$ and $\mathrm{A}-3$. Some of these problems must be solved before the hardware to be used for the first manned orbital flight can be tested on the engine. Because of the interaction of the varfous components of the engine and the multiplicity of modified designs yet to be proven, the commlttee judges that development testing could take longer than the current schedule allows. Fur ther no apparent adjustment to work plans on the test stands or provision of additional hardware to accommodate the shift of turbo machinery development testing to the complete engine was detected.

Analysis

With current developmental testing behind schedule and many redesigns still to be added to the system and proven, it is prudent to focus on the acquisition of an engine configuration sultable for early flights, thus minimfing potential shuttle program delays. It is time to consider the establishment of an interim engine developmental goal (see Flgure A-4) (Block I design) with performance and life limited to that adequate for safe early flights. Planning for the acquisition of a final (Block II) design to attain the final performance and life characteristics should begin immediately. Such thinking fits into current schedule projections by NASA and the contractor as shown by Figure A-4 on which the committee has added posstble Block I and Block II breakpoints. 


\section{SSME CONFIGURATION BASELINE}

MPTA (1.4)

- HPOTP (HIGH PRESSURE OXYGEN TURBOPUMP)

- Improved Balance-Reduced Synchronous Radial Loads

- Increased Bearing Preload

- Improved Turbine Bearing Coolant Flow

- HPFTP (HIGH PRESSURE FUEL TURBOPUMP)

- Existing Heavy Turbine Blade Dampers

- Existing Turbine Platform Seals

- Turbine Blade Damper Side Platform Coating

- Bradelloy Turbine Tip Seal

- LOW PRESSURE LIQUID OXYGEN DUCT

- Existing Design

- Life Limited-2780 Seconds

- Limited-2 ${ }^{\circ}$ Gimballing @ 90\%

Source: Rocketdyne Division Rockwell International

Figure A-2 


\section{SSME CONFIGURATION CHANGES-STEP 1}

MPTA (5-7)

- HPFTP

- Machined Damper Precision Fit-Up

- Faired Turbine Struts

- Six Segment Rene'/Nickel Turbine Tip Seal

- Modified Leading Edge Turbine Platform Seals

- Damper Contact Platform Coating Removed

- LOX PRESSURE LOX DUCT

- Interim Design Flex Joints

- Life Limited-4500 Seconds

- Full Gimballing

- FUEL TURBINE TEMPERATURE REDUCTION

- Rebalance Preburner Injector Resistances $-70^{\circ}$ Source: Rocketdyne Division Rockwell International

Figure A-3 


\section{SSME CONFIGURATION VERIFICATION}

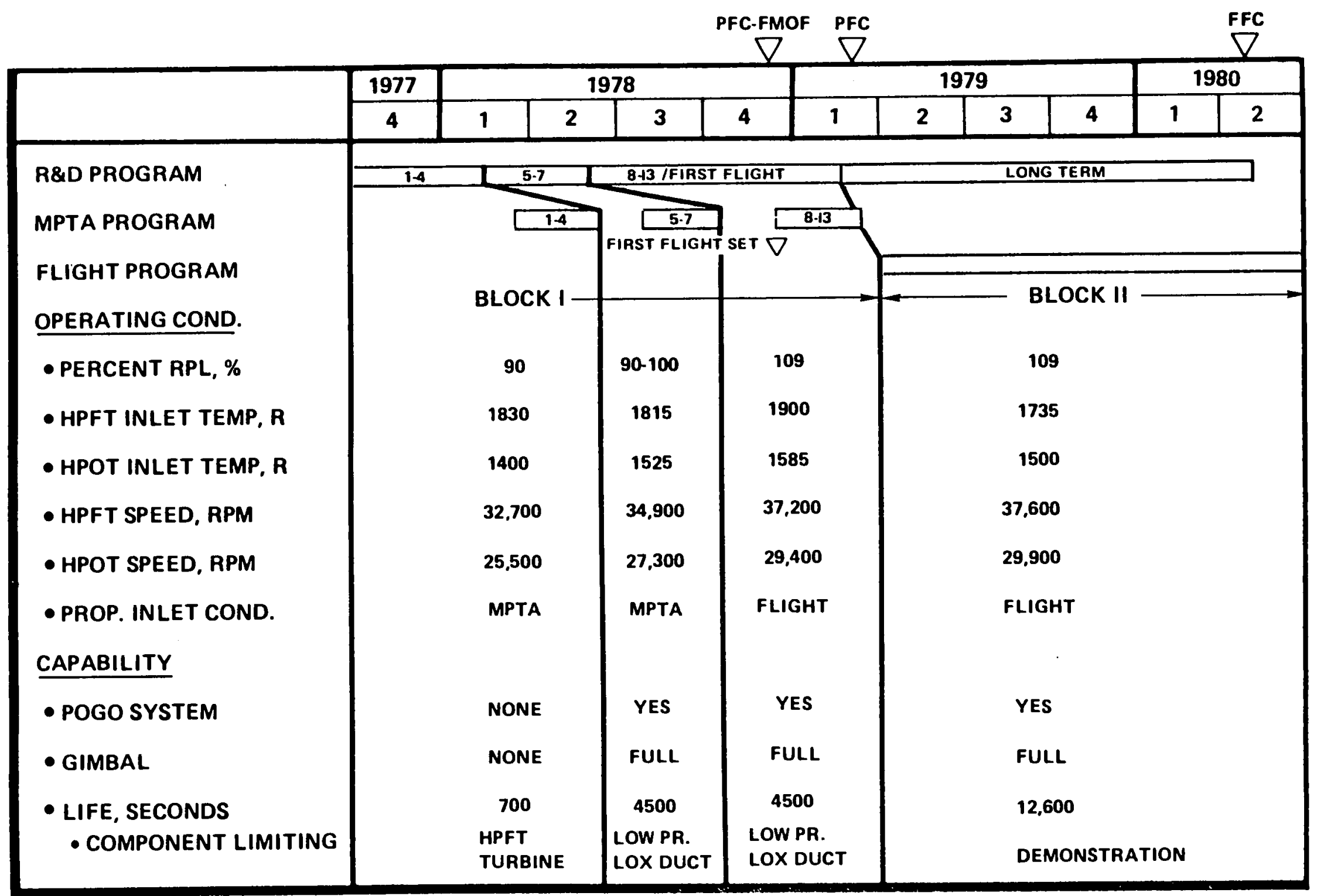




\begin{abstract}
APPENDIX B
NOTES ON

HIGH-PRESSURE FUEL TURBOPUMP TURBINE BLADE FAILURES
\end{abstract}

By

William Rostoker

During operation at rated power level of the space shuttle main engine a problem in the high-pressure fuel turbopump (HPFTP) became apparent. Two pump fallures are clearly due to fallure of one or two turbine blades. A third failure is attributed to a blade fallure, but no direct evidence is available. Rather, the evidence is a loss of turbine power. The status of each blade failure incldent is tabulated below.

$$
\begin{aligned}
& \text { 1. T/P } 0202 \mathrm{R} 1 \quad 8 \text { starts \& stops } 330 \mathrm{sec} \text { original design } \\
& \text { 2. TEST } 95 \quad 38 \text { " } 2,976 \mathrm{sec} \text { coated blades } \\
& \text { 3. } \mathrm{T} / \mathrm{P} 0202 \mathrm{R} 4 \quad 21 \quad 4,325 \text { (A) coated } \\
& 112,356 \text { (B) " }
\end{aligned}
$$

NOTE: A 47 blades with this usage

In the first case the fallure was attributed to damper lock-up. Calculation suggests the mean stress to be in the neighborhood of 55,000 pounds per square inch in this condition. Two blades were cracked; no separation occurred.

In the second case damper lock-up was also alleged to be the cause. The physical reason for the second fallure is different from the first. existed.

In the third case the pump was destroyed so no detailed evidence

Blade material: MAR-M-246, hafnium modified, directionally solidified (DS). Operating temperature: $1600-1700^{\circ} \mathrm{F}$ gas temperature with temperature spikes over $2000^{\circ} \mathrm{F}$.

Environment: hydrogen and steam, with blades subject to steady stress (centrifugal) plus vibratory stresses due to turbulence assoclated with struts supporting the main shaft bearing and the inlet guide vanes. The vibratory component of stress is to be reduced by a damper device between the turbine blades. The blades are subject to high-frequency fluctuating stresses superimposed on a large static stress level leading to a high cycle fatigue possibility. Blades also 
are subject to a hydrogen quench at the end of a burn leading to thermal fatigue crack possibilities

Three sets of turbine blade fallures:

1. $\mathrm{T} / \mathrm{P} 0202 \mathrm{R} 1$ uncoated blades, original turbine design, $330 \mathrm{sec}$. total run Involving 8 starts and stops. Blade platform and tree root gold-plated to reduce $\mathrm{H}_{2}$ absorption. Damper surfaces $\mathrm{N} 1$ plated.

Two blades discovered with cracks but no severence - one crack started at the leading edge, near the base of airfoll. Another crack started at the tralling edge, higher up from the base. Cracks ran across the grain.

Reputed reason for cracking: damping eliminated because Au-N1 fused the blades together.

2. Test 95

Coated blades (NiCrAlY $\left(0.003^{\prime \prime}\right)+\mathrm{ZrO} 2\left(0.004^{\prime \prime}\right)$

No Au coating. N1 coating on damper surfaces. $2976 \mathrm{sec}$. total run - 38 starts and stops.

One fractured blade - crack started at leading edge near base of alrfoll.

One cracked blade ( 3 blades away) at same location.

Reputed reason for cracking: temperature spike over $2100^{\circ} \mathrm{F}-1 \mathrm{sec}$ allowed softened N1 coat to extrude up Into space between damper and blade causing seizing and elimination of damper action.

3. $\mathrm{T} / \mathrm{P} 0202 \mathrm{R} 4$

Test 147, coated blades, no $\mathrm{Au}$, no $\mathrm{N} 1$ coatings

Mix of blades: 47 - with $4,325 \mathrm{sec}$ life (21 starts \& stops)

16 - with 2,356 sec life (11 starts \& stops)

The replacement of 16 blades because of thermal fatigue cracks in the platform although no fallures had occurred there. Pump lost power, ceased to pump $\mathrm{H}_{2}$ although $\mathrm{O}_{2}$ flow continued. Hot turbine $+0_{2}$ led to catastrophic oxidation and melting. Blade evidences obliterated. No way of knowing if a blade fracture began the events.

Fracture and Crack Appearances

Inftiation (Stage I) flat, cleavage like, transgranular basically same appearance as in laboratory high cycle fatigue tests. Hence 
deduced as high cycle fatigue fracture. Thermal fatigue does not seem to be an initiating factor. Fatigue cracks do appear on the platform but not on the leading or trailing edges.

Fatigue cracks progress nearly halfway across the blade before fast fracture takes over.

\section{Crack or Fracture Frequency}

1. $\mathrm{T} / \mathrm{P} 0202 \mathrm{R} 1$

2 cracked blades. 61 uncracked blades in first stage

$100 \%$ inspection showed no visible cracks in the 61 .

2. Test 95

2 cracked blades, 61 uncracked blades in first stage ( $100 \%$ inspection) at $639 \mathrm{sec}$ (13 starts and stops) full inspection showed no cracks in any blade.

3. $\mathrm{T} / \mathrm{P} 0202 \mathrm{R} 4$

At $2,000 \mathrm{sec}(2,356 \mathrm{sec}$ before fallure) all $63 \mathrm{blades}$ in the first stage were crack-free in airfoll, although there were thermal fatigue cracks in the platform.

\section{Discussion}

There have never been more than 2 cracked blades among the 63 in the first stage. There are two possible interpretations that can be inferred:

a. Two blades out of 63 contained microscopic crack-1ike flaws that escaped detection. Quality control by the supplier requires flaw detection by dye penetrant ( 0.010 in resolution), X-ray radiographic and visual. These are not 1ikely to detect microscopic, especially sub-surface, flaws.

b. Two blades failed out of 63 represent the normal low probability of early fallure in a distribution of failure lives that spans over a ten-fold range.

Actually a. and b. are the same. The random occurrence of microscopic flaws not detectable by present art provides for the wide range of fatigue levels of normally identical products. At the time of early failure, possible cracks in the remainder could still be too small to be resolvable.

Rocketdyne staff are inclined to accept the range of high cycle fatigue resistance as state-of-the-art for turbine blades. Elimination of such microscopic flaws as shrinkage porosity, non-metallic inclusions and carbide networks are not expected to be feasible or necessary. They expect to eliminate early fractures by reducing the 
fluctuating stress component by redesigning the struts in the hot gas inlet and by redesigning the dampers between blades to more efficiently reduce fluctuating stresses.

Note that no blade fallures (fracture or cracking) have been observed in the second stage although the static (centrifugal) stresses are the same. However, the gas temperature is lower but the primary reputed difference is that the dynamic stress components are much less than in the first stage.

An Important but lost study opportunity would have been to analyze, experimentally, the reduced fatigue life of the surviving, uncracked blades. This would have demonstrated whether sub-microscopic cracks had developed but were beyond resolution or that the blades were not of reduced fatigue life -- In which case the two falled blades (In each case) must have been flawed.

\section{Conclustons}

1. Coatings are not an issue in blade craçking.

2. Thermal fatigue is not an 1ssue in blade cracking.

3. The DS MAR-M-246 hafnium-modified material is probably as good a blade alloy as laboratory testing will indicate.

4. The quality of casting and the sensitivity of quality control is limited so that high cycle fatigue performance has a large range, 1.e., fatigue life at a given stress fluctuation can vary from shortest to longest by a factor of ten. This statement represents the state-ofthe-art.

5. The turbulence-generated fluctuating stress component should be reduced by modifled strut design, if possible.

6. Re-designing the damper will probably reduce the fluctuating stress component on the leading edge as well as the tralling edge of the alrfoll, but this cannot be verified until full testing of a single engine is completed.

7. Unless there is a new approach to screening and rejecting potentially low performance blades (high cycle fatigue) and unless the cycle service stresses can be reduced, the expectation of reducing fatigue fallures to zero for the life of the turbine is not optimistic. The evidence is not adequate to determine any metallurgical hypothesis for fallure. It could be due to a non-detectable flaw that is to be expected in the tall of the distributor functions or it could be due to a flaw that is a result of lack of procedural control. The characterizations 
of the material, particularly the spread in the fatigue behavior, are incomplete and should be completed.

8. The blades are less likely to be a problem if the temperature is reduced $350-500^{\circ} \mathrm{F}$. , as proposed by the contractor. 